\title{
Shear flow induces amyloid fibril formation
}

\author{
Elisabeth K. Hill, ${ }^{1}$ Benjamin Krebs, ${ }^{1}$ Dianna G. Goodall, ${ }^{1}$ Geoffrey J. Howlett, ${ }^{2}$ Dave E. Dunstan ${ }^{1,{ }^{*}}$
}

\section{SUPPORTING INFORMATION}

\section{Figure S1}

Unsheared native $\beta$-lg does not contain the large aggregated amyloid precursors observed in Figure 4a. Features in the AFM image shown in Supplementary Figure S1 have sub-nanometer heights.

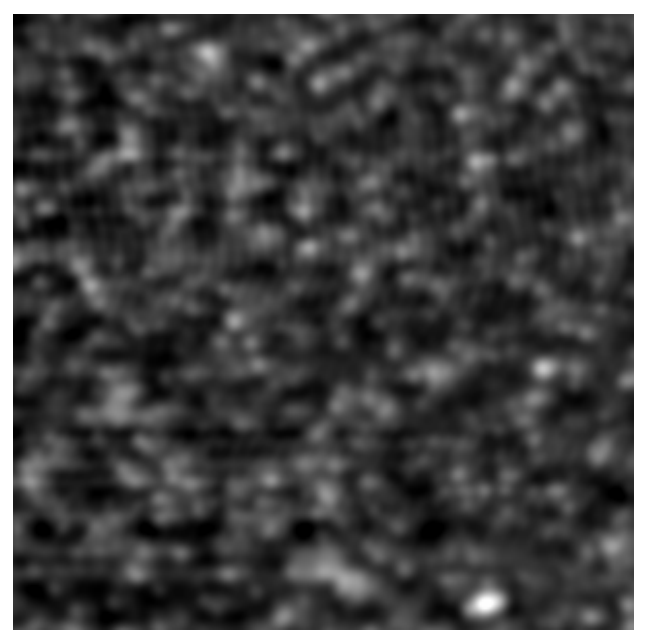

SUPPLEMENTARY FIGURE S1. AFM height image of unsheared $\beta$-lg deposited on mica. Image size is $1.2 \mu \mathrm{m} \times 1.2 \mu \mathrm{m}$. Height scale $<1 \mathrm{~nm}$. 


\section{Figure S2}

Supplementary Figure S2 confirms that fibrils are formed when sheared $\beta$-lg solutions are incubated with further $\beta$-lg. The spheroidal aggregates formed in shear act as seeds for amyloid formation.

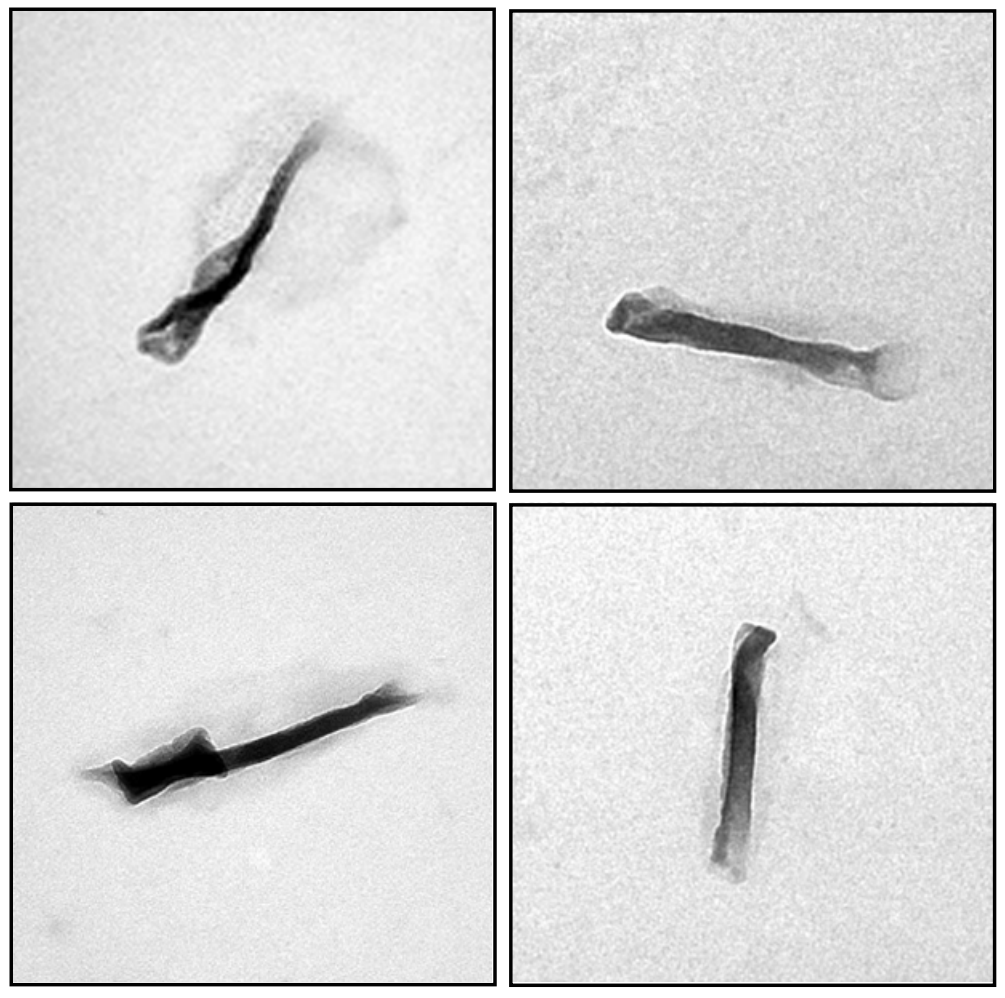

SUPPLEMENTARY FIGURE S2. TEM images of fibrils seeded by incubation with sheared protein solution. Each image shows an area approximately $0.5 \mu \mathrm{m}$ x $0.5 \mu \mathrm{m}$. Image was taken using a Phillips CM120 TEM. 